\title{
ABSTRAK \\ APLIKASI EKOLOGI UNTUK MENCARI KEBENARAN \\ DALAM MEMBINA MASYARAKAT UNTUK PENGELOLAAN LINGKUNGAN
}

\section{Asyik Nur Allifah AF, Dosen Program Studi Pendidikan Biologi, Universitas Darussalam, Ambon, 085233374844, E-mail: allif_af@yahoo.com}

Lingkungan adalah pusat dari semua kehidupan dan pengembangan setiap aktifitas yang berbeda. Komponen yang berhubungan dengan lingkungan juga berlangsung dalam tatanan ekonomi bahkan perubahan-perubahan sebagai hasil komponen dalam kerugian yang sangat berpengaruh pada semua aspek.Aplikasi ilmu ekologi dengan prinsip-prisip dasarnya apabila dipergunakan secara benar dan bertanggungjawab sebenarnya dapat memperbaiki segala kerusakan yang telah terjadi dan mencegah terulangnya peristiwa-peristiwa yang sangat tidak diinginkan.Masalah lingkungan yang dihadapi saat ini antara lain adalah menyikapi kebijakan pemerintah yang mengarah pada pengembangan sektor industri berdampak pada permasalahan lingkungan hidup yang mulai meluas mencakup berbagai kegiatan sektor industri. Di satu sisi industri memberikan kontribusi yang cukup berarti dalam perekonomian Indonesia di sisi lain juga menimbulkan berbagai masalah lingkungan baik yang bersifat biofisik maupun sosial budaya

Kata kunci: ekologi, kebenaran, masyarakat, pengelolaan lingkungan

\section{THE APPLICATION OF ECOLOGY TO SEEK TRUTH IN FOSTERING COMMUNITY FOR ENVIRONMENTAL MANAGEMENT}

The environment is the center of all life and the development of each of the different activities. The component that is associated with the environment also takes place in the economic order even those changes as a result of components in a highly influential losses on all aspects. Application of the science of Ecology with the fundamental principles of the essence when used correctly and are responsible for actually can repair any damage that has occurred and prevent the recurrence of events that are very undesirable. Environmental issues confronting the present among others are addressing government policies that lead to the development of the industrial sector had an impact on the environmental problems that began expanding the 
industrial sector covers a wide range of activities. On the one hand the industry contributes a pretty mean in Indonesia's economy on the other hand also gives rise to a variety of environmental problems that are both biophysical and socio-cultural

Keywords: ecology, sustainable, environmental management

\begin{abstract}
Undang-undang Penanaman
Modal Asing dan Penanaman Modal dalam Negeri, yang diberlakukan saat ini dimulai dengan pembangunan ekonomi di Indonesia. Modal asing yang masuk ke Indonesia diarahkan ke sektor industri dan pertambangan. Sejak diberlakukannya undang-undang tersebut sector industri mengalami peningkatan pertumbuhan dari tahun ke tahun. Kebijakan pemerintah yang mengarah pada pengembangan sector industri berdampak pada permasalahan lingkungan hidup yang mulai meluas mencakup berbagai kegiatan sektor industri. Di satu sisi industri memberikan kontribusi yang cukup berarti dalam perekonomian Indonesia di sisi lain juga menimbulkan berbagai masalah lingkungan baik yang bersifat biofisik maupun sosial budaya.
\end{abstract}

\section{PEMBAHASAN}

Dalam sosial budaya, strategi pembangunan yang diarahkan pada pengembangan industri telah mengubah berbagai tatanan masyarakat lokal. Perubahan tatanan masyarakat tersebut diakibatkan oleh sikap dan persepsi masyarakat terhadap adanya industri yang berkembang di lingkungannya. Munculnya pabrik industri dalam suatu wilayah dapat menimbulkan dampak positif dan negatif bagi kehidupan masyarakat di wilayah tersebut. Dampak positif dari kehadiran pabrik adalah:

1) membuka lapangan kerja bagi penduduk setempat,

2) membuka lapangan kerja di bidang sektor informal,

3) meningkatkan ekonomi daerah setempat

4) menambah pendapatan asli daerah bagi daerah tersebut.

5) perindustrian menghasilkan aneka barang yang dibutuhkan oeh masyarakat

6) mengurangi ketergantungan Negara pada luar negeri.

Adapun dampak negatif adalah:

1) menimbulkan kebisingan, polusi dan pencemaran oleh limbah industri yang berbahaya bagi lingkungan, 
2) beralihnya fungsi tataguna lahan

3) asap-asap pabrik menimbulkan polusi udara.

4) persentuhan budaya yang bisa menimbulkan berbagai masalah sosial.

Salah satu sektor industri yang berkembang saat ini diantaranya adalah pabrik yang bergerak di bidang pembuatan kaleng. Pabrik kaleng biasanya memproduksi kaleng dari bahan yang telah berupa lembaran, baik itu aluminium atau baja. Dampak negatif pabrik terutama mengenai masyarakat sekitar lokasi. Masyarakat yang relatif dari berbagai kalangan dan mempunyai latar belakang yang berbeda, baik pendidikan, mata pencaharian dan pendapatan. Dalam keadaan masyarakat yang mempunyai pendidikan dan pendapatan rendah mudah terprovokasi. Konflik dapat terjadi antara pengelola pabrik dengan masyarakat sekitar.

Kaleng didefinisikan sebagai wadah berbentuk sileinder yang memiliki bagian mulut terbuka, biasanya terbuat dari lembaran aluminium atau baja berlapis timah, dapat juga dibuat menggunakan plastic dengan cara moulding injeksi maupun molding tiup.
Tipe kaleng logam umumnya terbagi menjadi 2 kelompok dengan bentuk yang beraturan yaitu bulat (Round Can) dan kotak/persegi (Rectangular Can) tetapi dengan banyak sekali jenis dan ukuran. Adapun bentuk kaleng bulat dan persegi secara umum adalah:

\section{Round Can}

Adalah kaleng metal yang berbentuk fisik secara visual berupa lingkaran atau bulat dengan unsur penyusunnya berupa komponen body dan end serta asesoris pelengkap sesuai fungsi dan kegunaannya

\section{Rectanguler Can}

Adalah kaleng metal yang berbentuk fisik secara visual berupa kotak persegi dengan sudut beradius dirangkai dari unsur penyusunnya berupa komponen body dan asesoris pelengkap sesuai fungsi dan kegunaannya. Sedangkan standart Internasional yang banyak di produksi hampir disebagian besar industri kaleng dunia adalah:

a. Aerosol can, contoh: kaleng parfum

b. Beer-beveranges can, contoh kaleng beer \& beverges (soft drink)

c. Flat, hinged-lind tins can, contoh: kaleng tempat obat 
d. Flat top cylinders can, contoh: kaleng semir

e. Non reclosure cans, contoh: kaleng sardines

f. Reclosure cans, contoh: kaleng permen, susu

g. Oblong F-style cans, contoh: kaleng varnish, politer, insektisida

h. Oblong key opening cans, contoh: kaleng corned beef

i. Oval \& oblong cans dengan corong panjang, contoh: kaleng minyak, oli

j. Pear-shape key opening cans, contoh: kaleng daging

k. Multiple friction round cans, contoh: kaleng cat

1. Sanitary/open top cans, contoh: kaleng manisan buah, sayuran

m. Spice cans, contoh: kaleng manisan buah, telur

n. Square-breasted cans, contoh: kaleng makanan, susu

Bahan baku (tinplate) lebih dahulu diperiksa apakah memenuhi kwalitas dan sesudah itu diteruskan ke bagian pencetakan/pelapisan untuk di beri dekorasi atau dilapisi coating (protektiv). Proses tersebut disesuaikan dengan kebutuhan/permintaan pelanggan sehingga pengerjakannya satu dengan yang lain akan berlainan.

Industri atau pabrik dapat menghasilkan dampak negatif berupa: (1) Pencemaran air yaitu bahan-bahan pencemaran air dapat berupa senyawa organic dan logam-logam berat. Senyawa organic bisa berasal dari pabrik-pabrik yang menghasilkan senyawa organic tersebut yaitu detergent, pestisida atau limbah organic lainnya. Sedangkan logam berat berasal dari pabrik-pabrik yang mengunakan logam berat tersebut, contohnya merkuri $(\mathrm{Hg}), \mathrm{Pb}, \mathrm{Cu}, \mathrm{Zn}$ dan lainnya; (2) Pencemaran tanah yaitu pencemaran tanah dapat terjadi pada tanah itu sendiri atau melalui rembesan air yang tercemar. Adapun bahan-bahan pencemaran tanah seperti yang terjadi pada pencemaran air; dan (3) Pencemaran udara yaitu pencemaran udara dapat berupa gas-gas dan suara. Gas-gas dapat berupa asap, $\mathrm{CO}_{2}, \mathrm{CO}, \mathrm{NH}_{3}, \mathrm{H}_{2} \mathrm{~S}$ dan gasgas lainnya.

Suara atau bunyi didefinisikan sebagai getaran yang ditransmisikan melalui suatu medium elastis (misalnya udara) yang kemudian diterima dan dipersepsi oleh telinga manusia. Suara atau bunyi juga merupakan bentuk 
gelombang getaran suara yang merambat sebagai gelombang longitudinal dalam medium padat, cair dan gas (Achmadi 1994). Bunyi mempunyai dua aspek yang Menimbulkan ketulian pada pendengaran manusia, yaltu frekuensi dan intensitas. Frekuensi adalah banyaknya getaran per detik (cps = cycle per second atau hertz). Pendengaran manusia berada pada kisaran bunyi antara 20-20.000 Hz, sedangkan frekuensi pembicaraan adalah 275-2.500 Hz (Peterson 1997 dalam Santoso 1992). Intensitas adalah variasi tekanan dari suatu bunyi dengan satuan yang dinyatakan dalam desibel (dB). Makin besar intensitas bunyi, makin keras pula bunyi terdengar.

Bunyi atau suara yang dihasilkan dapat menimbulkan polusi suara yaitu berupa kebisingan. Kebisingan adalah suara atau bunyi yang tidak diinginkan dan menganggu. Tingkat kebisingan ditentukan oleh jenis kebisingan. Adapun jenis-jenis kebisingan antara lain:

1. Kebisingan kontinyu yaitu kebisingan dimana fluktuasi dari intensitasnya tidak lebih dari $6 \mathrm{~dB}$ dan tidak terputus-putus. Kebisingan ini dibedakan menjadi dua yaitu: a. Wide spectrum adalah kebisingan dengan spectrum frekuensi yang luas, seperti suara kipas angin, suara mesin tenun.

b. Narrow spectrum adalah kebisingan dengan spectrum sempit seperti suara sirine, generator, gergaji sirkuler

2. Kebisingan yang terputus-putus (intermittent) adalah kebisingan yang berlangsung secara tidak terus menerus, misalnya: lalu lintas kendaraan bermotor, kereta api, kapal terbang.

3. Kebisingan impulsif sesaat (impulsive noise) adalah kebisingan dengan intensitas yang agak cepat berubah, misalnya pukulan palu, tembakan meriam, ledakan bom.

4. Kebisingan impusif yang berulang, sebagai contoh adalah kebisingan yang ditimbulkan oleh mesin tempa pada pemancangan tiang beton

Untuk mengukur tingkat pencemaran di suatu tempat digunakan parameter pencemaran. Parameter pencemaran digunakan sebagai indikator (petunjuk) terjadinya pencemaran dan tingkat pencemaran yang telah terjadi Parameter pencemaran meliputi parameter 
fisik, parameter kimia, dan parameter biologi.

1. Parameter Fisik: Parameter fisik meliputi pengukuran warna, rasa, bau, suhu, kekeruhan dan radioaktivitas.

2. Parameter Kimia: Parameter kimia dilakukan untuk mengetahui kadar $\mathrm{CO}_{2}, \mathrm{pH}$, keasaman, kadar logam, dan logam berat. Sebagai contoh berikut disajukan pengukuran $\mathrm{pH}$ air, kadar $\mathrm{CO}_{2}$, dan oksigen terlarut.

a. Pengukuran $\mathrm{pH}$ air Air sungai dalam kondisi alami yang belum tercemar memiliki rentangan $\mathrm{pH}$ 6,5 - 8,5. Karena pencemaran, $\mathrm{pH}$ air dapat menjadi lebih rendah dari 6,5 atau lebih tinggi dari 8,5. Bahan-bahan organik biasanya menyebabkan kondisi air menjadi lebih asam. Kapur menyebabkan kondisi air menjadi alkali (basa). jadi, perubahan $\mathrm{pH}$ air tergantung kepada macam bahan pencemarnya. Perubahan nilai $\mathrm{pH}$ mempunyai arti penting bagi kehidupan air. Nilai $\mathrm{pH}$ yang rendah (sangat asam) atau tinggi (sangat basa) tidak cocok untuk kehidupan kebanyakan organisme. Untuk setiap perubahan satu unit skala pH (dari 7 ke 6 atau dari 5 ke 4) dikatakan keasaman naik 10 kali. Jika terjadi sebaliknya, keasaman turun 10 kali. Keasaman air dapat diukur dengan sederhana yaitu dengan mencelupkan kertas lakmus ke dalam air untuk elihat perubahan warnanya.

b. Pengukuran kadar $\mathrm{CO}_{2}$ : $\mathrm{Gas} \mathrm{CO}_{2}$ juga dapat larut ke dalam air. Kadar gas $\mathrm{CO}_{2}$ terlarut sangat dipengaruhi oleh suhu, $\mathrm{pH}$, dan banyaknya organisme yang hidup di dalam air. Semakin banyak organisme di dalam air, semakin tinggi kadar karbon dioksida terlarut (kecuali jika di dalam air terdapat tumbuhan air yang berfotosintesis). Kadar gas CO dapat diukur dengan cara titrimetri.

c. Pengukuran Kadar Oksigen Terlarut: Kadar oksigen terlarut dalam air yang alami berkisar $5-7$ ppm (part per million atau satu per sejita; $1 \mathrm{ml}$ oksigen yang larut dalam 1 liter air dikatakan memiliki kadar oksigen 1 ppm). Penurunan kadar oksigen terlarut dapat disebabkan oleh tiga hal: (1) Proses oksidasi (pembongkaran) bahanbahan organik; (2) Proses reduksi 
oleh zat-zat yang dihasilkan baktri anaerob dari dasar perairan; dan (3) Proses pernapasan orgaisme yang hidup di dalam air, terutama pada malam hari. Pencemaran air (terutama yang disebabkan oleh bahan pencemar organik) dapat mengurangi persediaan oksigen terlarut. hal ini akan mengancam kehidupan organisme yang hidup di dalam air. Semakin tercemar, kadar oksigen terlerut semakin mengecil. Untuk dapat mengukur kadar oksigen terlarut, dilakukan dengan metode Winkler. Parameter kimia yang dilakukan melalui kegiatan pernapasan jasad renik dikenal sebagai parameter biokimia. contohnya adalah pengukuran BOD dan COD.

3. Parameter Biologi: Di alam terdapat hewan-hewan, tumbuhan, dan mikroorganisme yang peka dan ada pula yang tahan terhadap kondisi lingkungan tertentu. Organisme yang peka akan mati karena pencemaran dan organisme yang tahan akan tetap hidup. Siput air dan Planaria merupakan contoh hewan yang peka pencemaran. Sungai yang mengandung siput air dan planaria menunjukkan sungai tersebut belum mengalami pencemaran. Sebaliknya, cacing Tubifex (cacing merah) merupakan cacing yang tahan hidup dan bahkan berkembang baik di lingkungan yang kaya bahan organik,meskipun spesies hewan yang lain telah mati. Ini berarti keberadaab cacing tersebut dapat dijadikan indikator adanya pemcemaran zat organik. Organisme yang dapat dijadikan petunjuk pencemaran dikenal sebagai indikator biologis. Indikator biologis terkadang lebih dapat dipercaya daripada indikator kimia. Pabrik yang membuang limbah ke sungai dapat mengatur pembuangan limbahnya ketika akan dikontrol oleh pihak yang berwenang.

Pengukuran secara kimia pada limbah pabrik tersebut selalu menunjukkan tidak adanya pencemaran. Tetapi tidak demikian dengan makluk hidup yang menghuni ekosistem air secara terus menerus. Di sungai itu terdapat hewan-hewan, mikroorganisme, bentos, mikroinvertebrata, ganggang, yang dapat dijadikan indikator biologis. 
Dari cara pembuatan kaleng dan bahan yang digunakan maka pabrik kaleng menghasilkan limbah berupa potongan-potongan bahan yang akan dibawa lagi ke pabrik bahan untuk di daur ulang. Dengan demikian limbah yang dihasilkan tidak mencemari lingkungan sekitar. Limbah lain yang dihasilkan relatif tidak ada. Hal ini dibenarkan dengan adanya penelitian tentang parameter pencemaran di sekitar pabrik. Selain pengamatan terhadap bahan pencemar juga mengamati keadaan ekologi di sekitar pabrik. Dari hasil penelitian tersebut tidak ditemukannya bahan pencemar yang berbahaya dan keberadaan berbagai organisma masih melimpah di sekitar pabrik. Selain menghasilkan limbah seperti yang tersebut diatas pabrik juga menimbulkan polusi suara jika memproduksi kaleng yang besar seperti drum. Polusi suara yang ditimbulkan tergolong kebisingan impulsif yang berulang. Agar tidak mengganggu lingkungan, maka proses yang menghasilkan kebisingan hendaknya dilakukan di siang hari.

Agar tidak terjadi konflik antara pabrik Artawena Kencana dan masyarakat, maka perlu dilakukan pembinaan kepada masyarakat sekitar pabrik. Pengeloaan sikap dan Persepsi Masyaraka perlu dilakukan. Upaya pengelolaan lingkungan terhadap sikap dan persepsi masyarakat dilakukan berdasarkan pendekatan social ekonomi dengan pendekatan:

1. Melakukan sosialisasi kepada masyarakat tentang maksud dan tujuan pembangunan pabrik Artawena Kencana.

2. Menjelaskan kepada masyarakat tentang tahap-tahap proses produksi dari bahan mentah hingga menjadi produk kaleng dan kegiatan open house.

3. Menjelaskan kepada masyarakat kemungkinan adanya dampak yang ditimbulkan akibat produksi kaleng.

4. Memberikan bantuan dana untuk pembangunan sarana dan prasarana social kemasyarakatan.

5. Memberikan prioritas tenaga kerja dari masyarakat sekitar sesuai dengan keahliannya.

6. Ikut berperan dalam lembaga komunitas masyarakat.

Untuk meningkatkan citra baik dari perusahaan dapat dilakukan kegiatan 
pengelolaan lingkungan secara bersamasama.

\section{KESIMPULAN}

Keberadaan pabrik dapat menimbulkan baik dampak positif dan dampak negatif. Dari proses pada beberapa pabrik di kota besar ternyata tidak lepas dari kondisi menyamakan persepsi masyarakat dan pengelola industri terkait tentang pengelolaan lingkungan. Penelitian adanya pencemar dan kelimpahan organisme dapat menunjukkan layaknya keberadaan industri. Untuk memberikan citra baik pada masyarakat sekitar perlu dilakukan agar tidak terjadi konflik dengan masyarakat sekitar. Pendekatan dengan masyarakat sekitar hendaknya dilakukan dengan pendekatan sosial ekonomi dan tidak menggunakan pendekatan hukum.

\section{DAFTAR PUSTAKA}

Anonimous. 2010. Bagaimana Cara Membuat. Diakses tanggal 20 Mei 2010

Iskandar. Heri, 2007. Kajian Dampak Kebisingan (Dalam Lingkungan Pabrik) Terhadap Penurunan Tingkat Pendengaran Karyawan Di Kawasan Industri Kota Tangerang. Tesis

Mu'adz B.J, 2004. Aktivitas Humas Perusahaan Rokok dalam
Membentuk Citra pada Masyarakat Sekitar. Skripsi.

Vivi,Restu. dkk, 2011. Etika Manusia Terhadap Lingkugan, Konsep Etika Lingkungan, Manusia Pembina Lingkungan dan Usaha Pembinaannya. FKIP UNMUH. Jember 